\title{
Restoring a stream through retention of urban stormwater runoff: a catchment-scale experiment in a social-ecological system
}

\author{
Christopher J. Walsh ${ }^{1,2}$, Tim D. Fletcher ${ }^{1,3}$, Darren G. Bos ${ }^{1,4}$, and Samantha J. Imberger ${ }^{1,5}$ \\ ${ }^{1}$ School of Ecosystem and Forest Sciences, University of Melbourne, 500 Yarra Boulevard, Burnley, Victoria 3121 Australia
}

\begin{abstract}
Restoration of ecological structure and function of urban streams probably requires catchment-scale modification of drainage infrastructure, but such catchment-scale restoration attempts and their assessment are rare. They require stream ecologists to embrace the interdisciplinary challenges of studying the social-ecological systems that are urban catchments. We designed and monitored a catchment-scale experiment that involved the retrofit of urban stormwater infrastructure throughout an urban catchment to restore more natural hydrology, water quality, and consequently, ecological condition in the receiving stream. We worked with government authorities and the catchment community (residents and property owners) over several years to fund and implement 289 stormwater retention systems. The length of the project allowed adaptation of the experimental design to expand the project's breadth and of retention-system design to match community needs and catchment context. Planning provisions are particularly important for such an experiment to ensure that the effect of dispersed experimental treatments is not countered by creation of new connected impervious areas elsewhere in the catchment. Catchment-scale experiments can help to transform policy and practice, but their success requires substantial effort and time to build trust among the numerous, diverse stakeholders of human-dominated urban ecosystems. Researchers need to be prepared to adopt an adaptive approach to the implementation of such experiments and to play the lead role in seeking funds for the implementation of the on-ground works necessary to underpin the experiment.
\end{abstract}

Key words: watershed scale, stream restoration, urban stormwater, stormwater control measures

The influence of catchment land use on the ecological structure and function of streams (Allan 2004) is arguably greatest in urban catchments, where stormwater drainage connects impervious surfaces throughout catchments directly to streams (Walsh et al. 2005a). Urban stormwater runoff delivered through conventional drainage systems is a primary degrader of urban stream ecosystems (Walsh et al. 2005b, Wenger et al. 2009). With increasing awareness of stormwater runoff as a degrading process, investment in stormwater management approaches aimed at environmental protection has grown. These new approaches aim to reduce pollutant loads and to restore more natural flow regimes (Burns et al. 2012). For streams, flow-regime alteration by urban stormwater runoff (increased high-flow frequency and total flow volume, and reduced baseflow contributions) probably is as important a stressor as the pollution it carries (Walsh et al. 2012).

The design and spatial arrangement of stormwater control measures (SCMs) dispersed throughout catchments for improving both water-quality and flow regimes is a field in its infancy (Burns et al. 2012). The potential for such technologies to protect stream ecosystems remains untested (Roy et al. 2008). Thus, the need for catchmentscale experimental trials of dispersed SCMs designed for the protection and restoration of stream health is urgent.

We instigated a catchment-scale experiment to test whether new SCM technologies applied across an urban area encompassing the catchment of a small stream (Little Stringybark Creek [LSC]; Fig. 1A, B) could adequately alter flow- and water-quality regimes to elicit change in

E-mail addresses: ${ }^{2}$ cwalsh@unimelb.edu.au; ${ }^{3}$ timf@unimelb.edu.au; ${ }^{4}$ dbos@unimelb.edu.au; ${ }^{5}$ samantha.imberger@unimelb.edu.au

"BRIDGES is a recurring feature of FWS intended to provide a forum for the interchange of ideas and information relevant to FWS readers, but beyond the usual scope of a scientific paper. Articles in this series will bridge from aquatic ecology to other disciplines, e.g., political science, economics, education, chemistry, or other biological sciences. Papers may be complementary or take alternative viewpoints. Authors with ideas for topics should contact BRIDGES Co-Editors, Ashley Moerke (amoerke@lssu.edu) and Allison Roy (aroy@eco.umass.edu). 


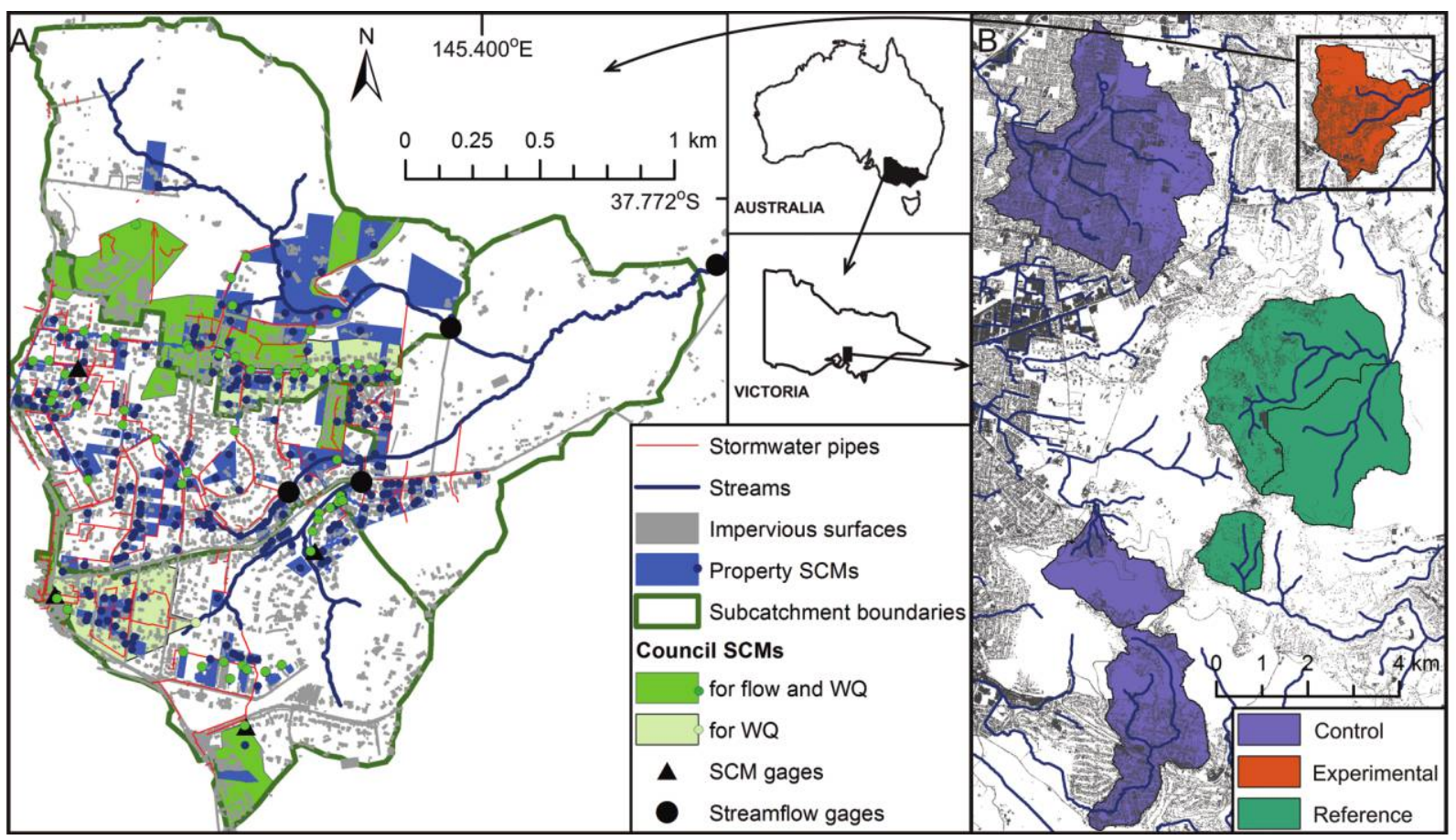

Figure 1. A.-Detail of the Little Stringybark Creek (LSC) catchment showing locations of impervious surfaces, catchments of stormwater control measures (SCMs; 237 installed by residents -5 installed independently of the project-and 58 installed by Yarra Ranges Council), and monitoring sites. All small- and some large-scale SCMs reduced storm flows through infiltration, harvesting, or evapotranspiration. Large-scale SCMs identified as 'for WQ' (water quality) are designed to provide filtration of base flows and small storm events and treat runoff from 2 large pipes. B.-The LSC (experimental) catchment and 3 control and 3 reference catchments, with impervious areas shown (gray).

in-stream ecological condition. The scale of the experiment has required a broader approach than is typical of stream ecological studies, and our study became a longterm social-ecological study (Collins et al. 2011). As described in other papers in this BRIDGES cluster, the experimental framework drove changes in behaviors of the catchment community (residents and property owners: Bos and Brown 2015), local government practices (Burns et al. 2015), and planning regulations (Prosser et al. 2015). In this paper, we describe the challenges for researchers embarking on such a large, public experiment, including how the experimental design required adaptation in response to the long period of project development and implementation. Our primary goal is to identify important lessons for researchers planning to conduct similar catchment experiments.

\section{HYPOTHESIS FORMULATION \\ AND EXPERIMENTAL DESIGN}

We hypothesized that the primary limitation to ecological structure and function in streams draining urban catchments was the combined effect of hydrologic and water-quality perturbations resulting from urban stormwater runoff delivered through constructed drainage sys- tems (Walsh et al. 2005a). To test this hypothesis, we developed design objectives for stormwater retention from impervious surfaces (Table 1; Walsh et al. 2012) with the goal of mimicking the hydrology of nearby forested catchments that support streams in good ecological condition.

The $1^{\text {st }}$ objective was to reduce the frequency and magnitude of polluted high flows from impervious surfaces by ensuring that SCMs had sufficient retention capacity to avoid overflow of untreated water in $\sim 95 \%$ of rain events (Walsh et al. 2009). The $2^{\text {nd }}$ and $3^{\text {rd }}$ objectives were to restore the quantity and quality of base flows lost by the construction of impervious surfaces (Hamel et al. 2013). The $4^{\text {th }}$ objective (reduction of runoff volume; Table 1 ) required substantial harvesting of storm water for internal uses (e.g., toilet flushing, hot water, laundry) or irrigation of open space to allow evapotranspiration losses. This objective was of least direct ecological importance, but we emphasize it because addressing the large increase in runoff volume was central to achieving the other objectives (Walsh et al. 2012).

These objectives can in theory be met by stormwater infiltration and harvesting systems built to treat impervious surface runoff at any scale from catchments up to the size of the largest subcatchment flowing to the stream requiring protection. However, SCMs at this largest scale 
Table 1. Calculation of and rationale behind the environmental benefit index: primary mechanisms by which urban stormwater degrades streams, the design objective for stormwater control measures (SCMs) to mitigate each effect, and the subindex used to estimate attainment of each objective. The index equals the mean of the 4 subindices. Perfect attainment of objectives for a $100-\mathrm{m}^{2}$ impervious surface would equal an environmental benefit score of 1. $A=$ the impervious catchment of the SCM $\left(\mathrm{m}^{2}\right), R=$ runoff frequency, $F V=$ filtered volume, $V=$ runoff volume. In each subindex, the objective takes 3 inferred values denoted by subscripts: $u=$ the urban state without SCM, $m=$ the urban state mitigated by the SCMs, $n=$ the pre-urban state ( 2 pre-urban values for $F V$ : forest or pasture). For further information on calculation of the indices see Walsh et al. (2010). TSS = total suspended solids.

\begin{tabular}{|c|c|c|}
\hline Effect of urban stormwater runoff & Objective for mitigation & Environmental benefit subindex \\
\hline $\begin{array}{l}\text { Increased frequency and magnitude } \\
\text { of high flows carrying pollutants; } \\
\text { dry-weather spills of pollutants } \\
\text { on impervious surfaces reaching } \\
\text { streams }\end{array}$ & $\begin{array}{l}\text { Minimize frequency of unfiltered } \\
\text { runoff from impervious surfaces } \\
\text { to streams }\end{array}$ & $\left(1-\max \left(\frac{R_{m}-R_{n}}{R_{u}-R_{n}}, 0\right)\right) A / 100$ \\
\hline Reduced contribution to base flows & $\begin{array}{l}\text { Restore volume and pattern of } \\
\text { filtered base flows lost by the } \\
\text { construction of impervious } \\
\text { surfaces (to between inferred } \\
\text { pre-urban forest and pasture } \\
\text { base flow; Zhang et al. 2001) }\end{array}$ & $\begin{array}{l}\text { If } F V_{m}<F V_{\text {forest }},\left(\frac{F V_{m}}{F V_{\text {forest }}}\right) A / 100 \\
\text { If } F V_{m}>F V_{\text {pasture }}, \\
\quad \max \left(0,1-\left(\frac{F V_{m}-F V_{\text {pasture }}}{F V_{\text {forest }}}\right)\right) A / 100 \\
\text { Else, } A / 100\end{array}$ \\
\hline $\begin{array}{l}\text { Poor dry-weather water quality } \\
\text { resulting from reduced base } \\
\text { flows and dry-weather } \\
\text { drainage inputs }\end{array}$ & $\begin{array}{l}\text { Contaminant concentrations } \\
\text { of filtered flows meet national } \\
\text { water-quality standards } \\
\text { (ANZECC and ARMCANZ 2000) }\end{array}$ & $\begin{array}{l}\text { Mean of }\left(1-\max \left(\frac{X]_{m}-[X]_{n}}{[X]_{u}-[X]_{n}}, 0\right)\right) A / 100 \\
\text { for each of }[X]=\text { median concentration } \\
\quad \text { of } \mathrm{P}, \mathrm{N} \text {, and TSS }\end{array}$ \\
\hline Increased total volume of runoff & $\begin{array}{l}\text { Reduce total runoff volume from } \\
\text { impervious surfaces to the } \\
\text { pre-urban streamflow volume }\end{array}$ & $\left(1-\max \left(\frac{V_{m}-V_{n}}{V_{u}-V_{n}}, 0\right)\right) A / 100$ \\
\hline
\end{tabular}

(end-of-subcatchment) are rarely able to meet the objectives in practice because of inadequate space to store large flow volumes (Burns et al. 2012). Thus, to restore a degraded stream in an existing urban catchment, SCMs are required at a range of catchment sizes, from part of a single building $\left(\sim 10^{2} \mathrm{~m}^{2}\right)$ to all roofs and roads in the catchment of an upland drainage line $\left(\sim 10^{4} \mathrm{~m}^{2}\right)$. Achieving such a multiscale outcome in the LSC catchment required engagement and collaboration with many catchment stakeholder groups: residents, businesses, the local government authority responsible for roads and drainage (Yarra Ranges Council [council]), and the regional authority responsible for the management of streams (Melbourne Water [MW]).

We selected LSC as the experimental catchment because it is degraded ecologically (we hypothesize as a result of urban stormwater runoff), but its connected impervious area is small enough to make tractable the number and extent of SCM retrofit works required to bring about an ecological response (Walsh et al. 2005a). The upper $2 \mathrm{~km}^{2}$ of the catchment is a typical suburban mix of residential housing at a range of densities and commercial, educational, and industrial precincts, whereas the downstream catchment is predominantly low-density, rural-residential land (Fig. 1A). The typical urban form in the developed part of the catchment is important because a goal of the project was to demonstrate the feasibility of stormwater retention for stream protection in urban areas.
We designed the experiment as an extension of a Beyond-BACI (Before-After-Control-Impact: Stewart-Oaten et al. 1986, Underwood 1991) design. In addition to comparing ecological patterns in the 'impact' stream (LSC) with those in equally degraded urban control streams, we included a comparison to reference streams in forested catchments that are not affected by urban stormwater runoff. This Before-After-Control-Reference-Impact (BACRI) design allows control for differential responses to factors, such as climate, between control and reference streams. We selected 3 reference and 3 control streams to compare with LSC (Fig. 1B) from sites monitored in a study that generated the primary hypothesis of the project (Walsh et al. 2005a). We have monitored these 7 streams since 2001 with some interruptions (Fig. 2) for water quality (using the methods of Hatt et al. 2004), algal biomass (Taylor et al. 2004) and assemblage composition (Newall and Walsh 2005), macroinvertebrate assemblage composition (Walsh 2004), and since 2011, leaf-breakdown rates (Imberger et al. 2008).

Prior to SCM installation in the LSC catchment, these indicators (Fig. 3A-D) varied within the ranges of the control streams, which demonstrated consistently poorer condition than the reference streams. These data suggest that the BACRI design provides a strong basis for inferring changes in ecological indicators from their current degraded state and, more importantly, an objective assess- 
BACRI Macroinvertebrate sampling

BACRI Water quality and other ecological sampling

Hydrographic monitoring

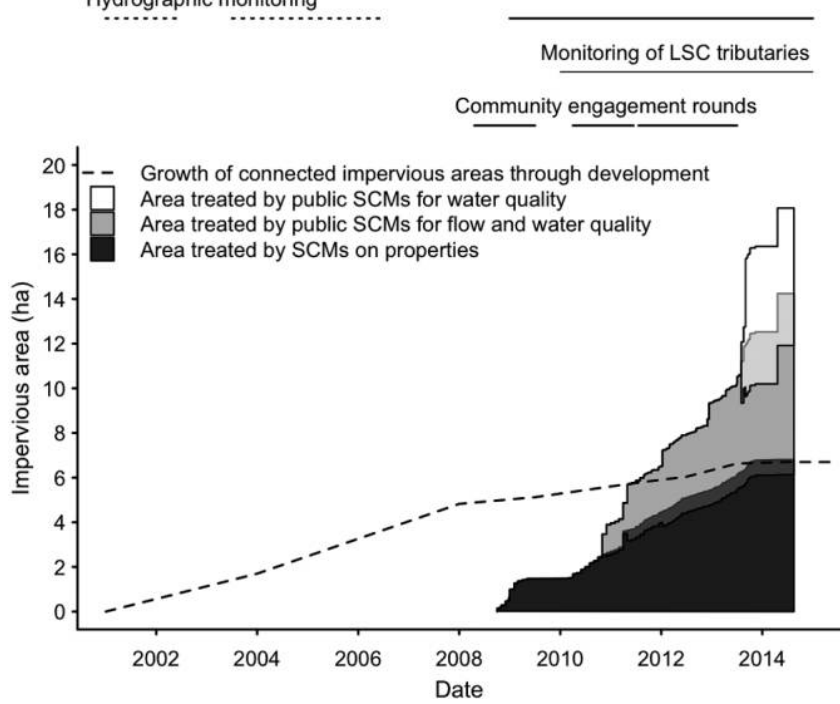

Figure 2. Timeline of the Little Stringybark Creek (LSC) project. Ecological, water-quality, and hydrographic variables were monitored with interruptions since 2001. Incomplete depth-logger records provide some hydrographic information prior to 2010, after which intensive campaigns to improve hydrographic rating tables resulted in more reliable data. The same variables were monitored in each of the 3 tributaries of LSC from 2010. Three rounds of community engagement began the installation of stormwater control measures (SCMs) on private properties in 2009, followed by SCMs built and maintained by Yarra Ranges Council in 2011. The 3 polygons portray the cumulative increase in impervious area treated by SCMs. In 2013, 2 systems designed to filter low flows only were installed at the end of 2 large pipes (SCMs for water quality). The 3 polygons overlap because the catchments of larger systems contain some smaller-scale systems.

ment of the magnitude of that change toward values observed in reference streams. The installation of SCMs to a level we hypothesized sufficient to change ecological indicators, took $4 \mathrm{y}$ (Fig. 2). No change in ecological indicators had been observed by early 2014 (Fig. 3A-D), with the exception of $\mathrm{P}$ concentrations, which suggest a shift from levels comparable to control streams to levels similar to reference streams (Fig. 3A). We do not present statistical analysis of these results because a longer period of monitoring is required for a robust inference of effect.

The long period of project development and experimental manipulation has permitted an expansion of the monitoring program and has provided a complementary analysis to the BACRI experiment. Since 2010 we have monitored the same variables in 3 tributaries of LSC (each with a catchment area of $\sim 1 \mathrm{~km}^{2}$ [Fig. 1A] and each with different levels of urbanization and potential for SCM implementation). Data from these additional sites, together with the main LSC sampling site $\sim 1 \mathrm{~km}$ downstream, per-
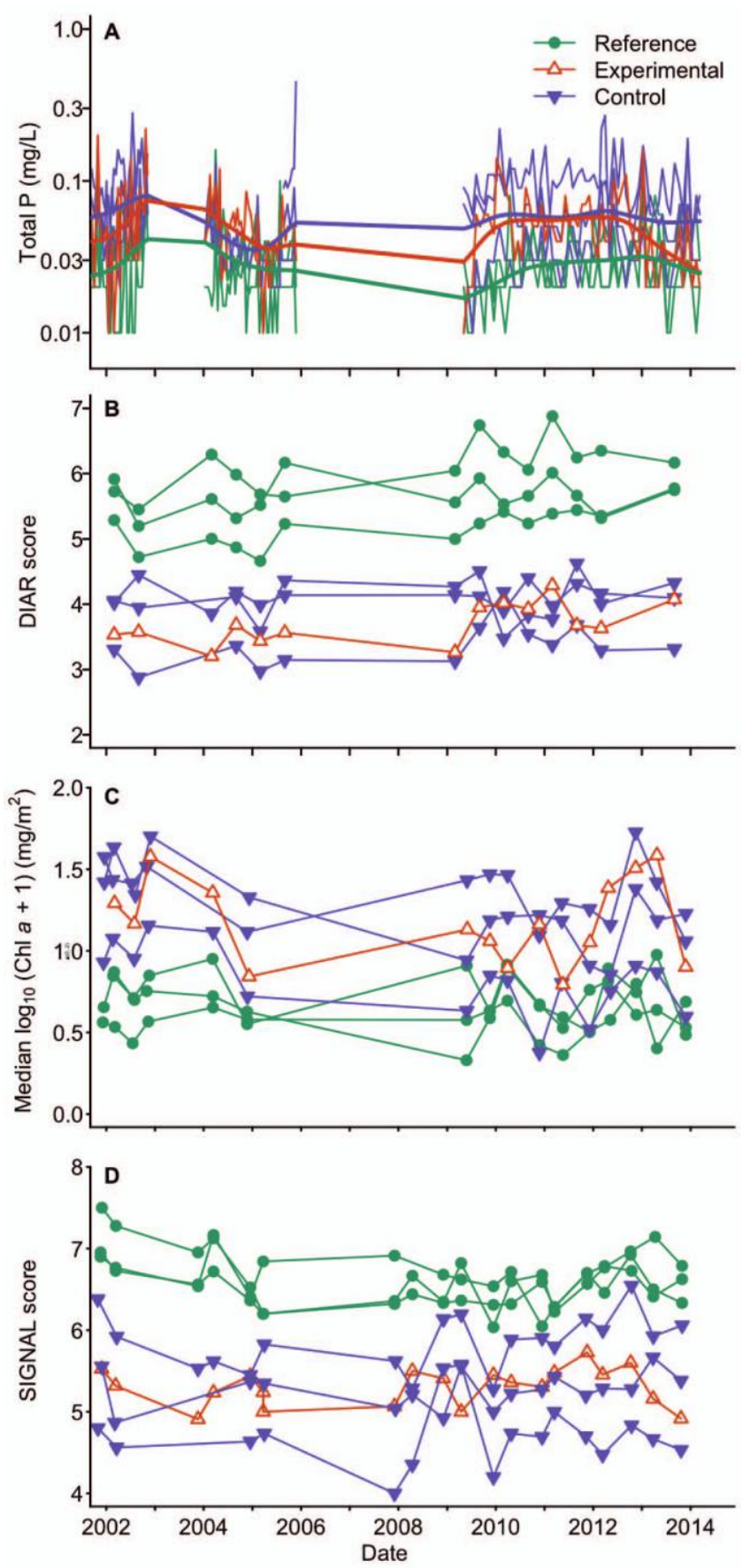

Figure 3. Sample of ecological indicators monitored in Little Stringybark Creek (LSC), 3 control streams, and 3 reference streams. A.-Total P, collected and analyzed using the methods of Hatt et al. (2004). Narrow lines show measured data, whereas thick lines are smoothed spline curves $(\mathrm{df}=10)$ to illustrate the trend of a shift in LSC away from control stream concentrations and toward those of reference streams. B.-DIAR, a diatom assemblage index (Chessman et al. 2007), collected using the methods of Newall and Walsh (2005). C.-Median benthic algal biomass (chlorophyll [Chl] $a$ collected and measured using the methods of Taylor et al. 2004). D.-Stream Invertebrate Grade Number Average Level (SIGNAL), a macroinvertebrate assemblage index (Chessman 1995), collected using the methods of Walsh (2004). 
mit a comparison of stream responses to varying degrees of stormwater retention.

We obtained funding for research associated with our monitoring programs, but our greater challenge was to obtain sufficient funding to implement the stormwater retention works to test our hypothesis. Such funding is of a different class than the funding that is more familiar to researchers, and seeking it required broader engagement with natural-resource management authorities, and collaborations outside our disciplines.

\section{SEEKING FUNDING FOR WORKS}

We began our search for works funding in 2005 after a scoping study of works required (Lloyd 2004), which estimated a total cost of AU\$3 million (2004 dollars). We approached MW, which had recently underwritten a smaller-scale paired-catchment study of stormwater retention in a greenfield development (Lloyd et al. 2002). After several meetings over several years with staff across various levels of the organization, we remained unsuccessful. The primary reason for rejection was that investing such a large amount in a single, small catchment would be politically unacceptable given MW's region-wide responsibility (Prosser et al. 2015).

We first gained funding for works in 2008, for a smaller-scale pilot without a primary focus on the health of the stream, from the Victorian Water Trust, which promoted water conservation. The pilot was proposed as an economic experiment using a reverse auction to encourage the installation of rainwater tanks and bioretention systems (Fletcher et al. 2011). MW and the Water Trust contributed AU\$300,000 to the 54 SCM projects that were built on private properties in the pilot.

This pilot was the catalyst for greater interest in the project, initially from MW, which in 2010 allocated a further AU\$1 million for works using an alternative auction process. This AU\$1 million permitted us to apply success- fully for Australian federal (Caring for our Country Investment Fund, AU\$800,000) and Victorian state government (Stormwater and Urban Water Recycling Fund, AU\$1 million) schemes that required matching funds. Thus, by 2011, we had raised sufficient funds to implement the catchment works we had scoped in 2004.

\section{IMPLEMENTING WORKS}

The implementation of the conceptual plans of Lloyd (2004) required flexibility and innovation to maximize stormwater retention in the varied contexts of properties and streetscapes in the catchment. The extended period of project implementation permitted an evolution of SCM designs over time. We financed SCMs on 231 private properties through 3 rounds of community engagement, each using a different market-based instrument (Table 2, Fig. 2; Bos and Brown 2015) to select the best-value projects. The reverse auctions of the $1^{\text {st }}$ and $2^{\text {nd }}$ rounds (Bos and Brown 2015, Nemes et al. 2015) determined the maximum price for SCMs implemented on private properties in the $3^{\text {rd }}$ round and for 58 SCMs constructed by council (Table 2).

To allow an objective assessment of the value of competing SCMs, we derived a scalable index of environmental benefit of stormwater retention systems. In Round 1, we used an index that was biased towards water conservation (a condition of our initial funding), but then revised the index to measure the degree to which each of the 4 design objectives (Table 1 ) were met by SCMs, scaled so that the perfect attainment of all 4 objectives for runoff from $100 \mathrm{~m}^{2}$ of impervious surface $=1$ (Fletcher et al. 2011). This index became the 'commodity' that each SCM potentially supplied, against which the cost could be assessed.

Almost all SCMs on private properties included rainwater tanks plumbed to internal household uses (at least toilet, usually laundry, and often hot water), with only 6 householders opting for a rain garden (vegetated infil-

Table 2. Types of stormwater control measures (SCMs) installed on private properties during each of the 3 rounds of community engagement in the Little Stringybark Creek project (Bos and Brown 2015) and those installed by Yarra Ranges Council (Burns et al. 2015). Two hundred thirty-seven property systems on 231 properties are listed. Six properties installed SCMs in $>1$ round.

\begin{tabular}{lcccc}
\hline \multicolumn{1}{c}{ SCM type } & Round 1 & Round 2 & Round 3 & Council \\
\hline Rainwater tank only & 41 & 21 & 1 & - \\
Tank + rain garden & 1 & 2 & 1 & 2 \\
Tank + infiltration system & 10 & 36 & 3 & - \\
Tank + passive irrigation to garden & - & 13 & 68 & - \\
Tank + baseflow trickle to stormwater & - & 2 & 36 & 9 \\
Rain garden only & 2 & - & - & 39 \\
Infiltration system only & - & - & - & 6 \\
Low-flow water quality (WQ) filtration system & - & - & \\
\hline
\end{tabular}


tration system) (Table 2, Fig. 4B). To promote greater use of infiltration, we first encouraged the use of simpler sublawn infiltration systems. We increasingly encouraged (after several successful trials) rainwater tanks with a dedicated volume for trickle-release to conventional gardens (Table 2, Fig. 4B; Burns et al. 2014). Such systems were cheaper to install than infiltration systems and allowed greater flexibility in space-constrained sites (Bos and Brown 2015).

The first SCMs constructed by council were large rain gardens draining $10^{3}-10^{4} \mathrm{~m}^{2}$ of impervious surface, intercepting council drainage pipes. The largest project we funded was an 800-kL harvesting scheme draining 2.3 ha of impervious area. The tanks overflowed to a series of rain gardens and provided irrigation for adjacent sports fields in summer, and trickled to a swale to mimic baseflow in winter. Council constructed (after successful trials) 30 small, minimal-design rain-garden systems that receive runoff from sections of roads through curb-cuts (Fig. 4A; Burns et al. 2015). We also constructed 2 filtration systems to deal with poor dry-weather water quality from large pipes in the catchment (Table 2, Council SCMs for water quality in Fig. 1A). The use of cost-per-environmentalbenefit-unit to evaluate potential projects ensured optimal selection of projects (Bos and Brown 2015), treating runoff from as much impervious area as possible.

A review of progress in 2011, after 2 y of implementing works, showed that we had installed SCMs intercepting runoff from $\sim 5$ ha of impervious surfaces. However, a revision of catchment impervious coverage data revealed that $\sim 5$ ha of new impervious surfaces had been constructed and connected to the stormwater drainage network since our first assessment in 2001 (Fig. 2). The realization that the progress of our works was being countered by new developments resulted in a valuable col- laboration with council and MW. Together, we established a special planning provision to ensure new developments meet the LSC project's stormwater runoff objectives (RossRakesh et al. 2012, Prosser et al. 2015).

\section{ACHIEVEMENTS AND LESSONS}

The goal of the LSC project is to test whether new SCM technologies dispersed across a catchment result in restoration of the ecological structure and function of a degraded urban stream. To date, this question remains unresolved. Most SCM implementation was achieved in July 2012-October 2013 (Fig. 2), and improvements to water quality were observed in October 2013-April 2014 (Fig. 3A). The rate and trajectory of ecological recovery in streams following removal or mitigation of stressors remains uncertain (Lake et al. 2007), but responses probably will span multiple years.

Our experiment was designed to manipulate the hydrology and water quality of runoff from impervious surfaces to a level beyond both common practice and local best-practice standards. Such a requirement led to 2 important consequences that should be planned for in other experiments designed to test the effects of management treatments that exceed standard practice. First, the SCMs that we implemented were necessarily innovative and required adaptation of designs to the catchment's infrastructure context and the needs of residents, while minimizing maintenance requirements. Critical to achieving these aims was a team of engineers skilled in SCM design, concerted efforts to engage residents on whose properties systems were built (Bos and Brown 2015), and council engineers who constructed and maintained public SCMs (Burns et al. 2015). This observation points to the need to take an adaptive approach. We modified the design of systems as we

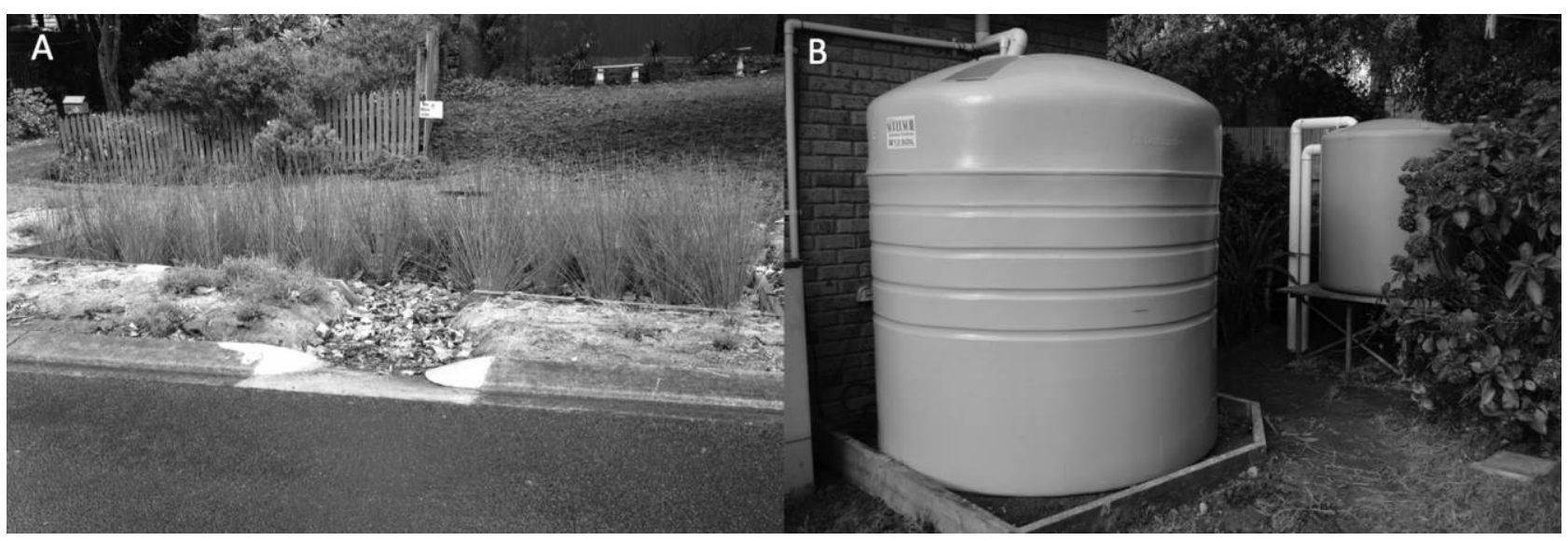

Figure 4. A.-A small infiltration system on a street curb in the Little Stringybark Creek (LSC) catchment. Stormwater flowing along the gutter is directed preferentially into the system by a curb cut. B.-A typical domestic harvesting system with primary tank for internal and external uses and overflow tank set for year-round passive irrigation of garden (most passive-irrigation designs are a single tank with a slow leak at a proportion of the tank volume). 
learned more about system performance, maintenance requirements, and public acceptance.

A $2^{\text {nd }}$ important lesson was the need to control new development in the catchment, which has the potential to undermine the aims of such a trial. The special planning provision developed for the LSC catchment is being considered a trial of future urban water-policy directions by MW, and the project has been used as an exemplar by the state government (Department of Environment and Primary Industries 2013).

The project's ability to transform the policy and practice of government authorities (Burns et al. 2015, Prosser et al. 2015), along with community awareness and behaviors (Bos and Brown 2015), suggests that catchmentscale experiments are potentially powerful tools for shortening the gap between scientific discovery and on-ground implementation. The success of such large-scale, multistakeholder endeavors rests on the successful building of relationships and trust, a conclusion echoing those of others who have sought to bridge scientific research and riverine management (e.g., Cullen 1990, Tomlinson and Davis 2010, Webb et al. 2010). Authors of such studies have often emphasized frictions between scientists and policy makers in building collaborations. Our collaborations have not been without difficulties, but the problems raised by urban stormwater present the possibility of mutual benefits to humans (provision of a water resource) and the environment (stream protection), rather than trade-offs (Walsh et al. 2012). Despite the potential for co-benefits, the challenges of building fruitful collaboration across many stakeholders to conduct a catchmentscale experiment in a human-dominated landscape remain. As evidenced in the following papers (Bos and Brown 2015, Burns et al. 2015, Prosser et al. 2015), building of trust is critical and takes time, ongoing work, and maintenance.

\section{ACKNOWLEDGEMENTS}

This work was supported by the Australian Research Council (ARC) Linkage Program (LP0883610 and LP130100295), the Cooperative Research Centre for Water Sensitive Cities, Melbourne Waterway Research Practice Partnership (funded by MW), Victorian Water Trust, Victorian Urban Stormwater and Recycling Fund, Caring for Our Country Investment Fund, Office of Living Victoria, Yarra Ranges Council, and Yarra Valley Water. TDF is supported by an ARC Future Fellowship (FT10010044).

\section{LITERATURE CITED}

Allan, J. D. 2004. Landscapes and riverscapes: the influence of land use on stream ecosystems. Annual Review of Ecology, Evolution, and Systematics 35:257-284.

ANZECC and ARMCANZ (Australian and New Zealand Environment and Conservation Council, and Agriculture and Resource Management Council of Australia and New Zealand). 2000. Australian and New Zealand guidelines for fresh and marine water quality. Volume 2. Aquatic ecosystems- rationale and background information. Australian and New Zealand Environment and Conservation Council, Agriculture and Resource Management Council of Australia and New Zealand, Canberra. (Available from: http://www.environment .gov.au/water/quality/publications/australian-and-new-zealand -guidelines-fresh-marine-water-quality-volume-2)

Bos, D. G., and H. L. Brown. 2015. Overcoming barriers to community participation in a catchment-scale experiment: building trust and changing behavior. Freshwater Science 34: 1169-1175.

Burns, M. J., T. D. Fletcher, A. R. Ladson, and C. J. Walsh. 2014. Flow-regime management at the urban land-parcel scale: a test of feasibility. Journal of Hydrological Engineering. doi:10 .1061/(ASCE)HE.1943-5584.0001002

Burns, M. J., T. D. Fletcher, C. J. Walsh, A. R. Ladson, and B. E. Hatt. 2012. Hydrologic shortcomings of conventional urban stormwater management and opportunities for reform. Landscape and Urban Planning 105:230-240.

Burns, M. J., E. Wallis, and V. Matic. 2015. Building capacity in low-impact drainage management through research collaboration. Freshwater Science 34:1176-1185.

Chessman, B. C. 1995. Rapid assessment of rivers using macroinvertebrates: a procedure based on habitat-specific sampling, family level identification and a biotic index. Australian Journal of Ecology 20:122-129.

Chessman, B. C., N. Bate, P. A. Gell, and P. Newall. 2007. A diatom species index for bioassessment of Australian rivers. Marine and Freshwater Research 58:542-557.

Collins, S. L., S. R. Carpenter, S. M. Swinton, D. E. Orenstein, D. L. Childers, T. L. Gragson, N. B. Grimm, J. M. Grove, S. L. Harlan, and J. P. Kaye. 2011. An integrated conceptual framework for long-term social-ecological research. Frontiers in Ecology and the Environment 9:351-357.

Cullen, P. 1990. The turbulent boundary between water science and water management. Freshwater Biology 24:201-209.

Department of Environment and Primary Industries. 2013. Improving our waterways: Victorian waterway management strategy. State of Victoria, Melbourne, Australia. (Available from: http://www.depi.vic.gov.au/water/rivers-estuaries-and -wetlands/strategy-and-planning)

Fletcher, T. D., C. J. Walsh, D. Bos, V. Nemes, S. RossRakesh, T. Prosser, B. Hatt, and R. Birch. 2011. Restoration of stormwater retention capacity at the allotment-scale through a novel economic instrument. Water Science and Technology 64(2):494-502.

Hamel, P., E. Daly, and T. D. Fletcher. 2013. Source-control stormwater management for mitigating the impacts of urbanisation on baseflow: a review. Journal of Hydrology 485:201-211.

Hatt, B. E., T. D. Fletcher, C. J. Walsh, and S. L. Taylor. 2004. The influence of urban density and drainage infrastructure on the concentrations and loads of pollutants in small streams. Environmental Management 34:112-124.

Imberger, S. J., C. J. Walsh, and M. R. Grace. 2008. More microbial activity, not abrasive flow or shredder abundance, accelerates breakdown of labile leaf litter in urban streams. Iournal of the North American Benthological Society 27: 549-561.

Lake, P. S., N. Bond, and P. Reich. 2007. Linking ecological theory with stream restoration. Freshwater Biology 52:597-615. 
Lloyd, S. 2004. Stream restoration through the application of Water Sensitive Urban Design: Little Stringybark Creek Catchment project. CRC for Freshwater Ecology, Monash University, Melbourne, Australia. (Available from: http://www .urbanstreams.unimelb.edu.au/Docs/Lloyd_2004.pdf)

Lloyd, S. D., T. H. F. Wong, and B. Porter. 2002. The planning and construction of an urban stormwater management scheme. Water Science and Technology 45(7):1-10.

Nemes, V., A. La Nauze, C. J. Walsh, T. D. Fletcher, D. Bos, S. RossRakesh, and G. Stoneham. 2015. Saving a creek one bid at a time: a uniform price auction for urban stormwater retention. Urban Water Journal. doi:10.1080/1573062X.1572014 .1988732

Newall, P., and C. J. Walsh. 2005. Response of epilithic diatom assemblages to urbanization influences. Hydrobiologia 532: $53-67$.

Prosser, T., P. J. Morison, and R. A. Coleman. 2015. Integrating stormwater management to restore a stream: perspectives from a waterway management authority. Freshwater Science 34:1186-1194.

RossRakesh, S., C. J. Walsh, T. D. Fletcher, V. Matic, D. Bos, and M. J. Burns. 2012. Ensuring protection of Little Stringybark Creek: evidence for a proposed design standard for new developments. Melbourne Waterway Protection and Restoration Science-Practice Partnership, The University of Melbourne, Melbourne, Australia. (Available from: http://www .urbanstreams.unimelb.edu.au/Docs/LSB_ESO_Technical_report -final.pdf)

Roy, A. H., S. J. Wenger, T. D. Fletcher, C. J. Walsh, A. R. Ladson, W. D. Shuster, H. W. Thurston, and R. R. Brown. 2008. Impediments and solutions to sustainable, watershedscale urban stormwater management: lessons from Australia and the United States. Environmental Management 42:344359.

Stewart-Oaten, A., W. W. Murdoch, and K. R. Parker. 1986. Environmental impact assessment: "psuedoreplication" in time? Ecology 67:929-940.

Taylor, S. L., S. C. Roberts, C. J. Walsh, and B. E. Hatt. 2004. Catchment urbanisation and increased benthic algal biomass in streams: linking mechanisms to management. Freshwater Biology 49:835-851.

Tomlinson, M., and R. Davis. 2010. Integrating aquatic science and policy for improved water management in Australia. Marine and Freshwater Research 61:808-813.

Underwood, A. J. 1991. Beyond BACI: experimental designs for detecting environmental impacts on temporal variations in natural populations. Australian Journal of Marine and Freshwater Research 42:569-587.

Walsh, C. J. 2004. Protection of in-stream biota from urban impacts: minimise catchment imperviousness or improve drainage design? Marine and Freshwater Research 55:317-326.

Walsh, C. J., T. D. Fletcher, and M. J. Burns. 2012. Urban stormwater runoff: a new class of environmental flow problem. PLoS ONE 7:e45814.

Walsh, C. J., T. D. Fletcher, B. E. Hatt, and M. Burns. 2010. New generation stormwater management objectives for stream protection: stormwater as an environmental flow problem. On disk in P. J. Morison (editor). Proceedings of the Stormwater Industry Association of Australia National Conference 2010. Stormwater Industry Association, Sydney, New South Wales, Australia. (Available from: http://www.stormwater .asn.au/publications)

Walsh, C. J., T. D. Fletcher, and A. R. Ladson. 2005a. Stream restoration in urban catchments through re-designing stormwater systems: looking to the catchment to save the stream. lournal of the North American Benthological Society 24:690705.

Walsh, C. J., T. D. Fletcher, and A. R. Ladson. 2009. Retention capacity: a metric to link stream ecology and storm-water management. Journal of Hydrologic Engineering 14:399-406.

Walsh, C. J., A. H. Roy, J. W. Feminella, P. D. Cottingham, P. M. Groffman, and R. P. Morgan. 2005b. The urban stream syndrome: current knowledge and the search for a cure. Journal of the North American Benthological Society 24:706723.

Webb, J. A., M. J. Stewardson, Y. E. Chee, E. S. G. Schreiber, A. K. Sharpe, and M. C. Jensz. 2010. Negotiating the turbulent boundary: the challenges of building a sciencemanagement collaboration for landscape-scale monitoring of environmental flows. Marine and Freshwater Research 61: 798-807.

Wenger, S. J., A. H. Roy, C. R. Jackson, E. S. Bernhardt, T. L. Carter, S. Filoso, C. A. Gibson, W. C. Hession, S. S. Kaushal, E. Martí, J. L. Meyer, M. A. Palmer, M. J. Paul, A. H. Purcell, A. Ramírez, A. D. Rosemond, K. A. Schofield, E. B. Sudduth, and C. J. Walsh. 2009. Twenty-six key research questions in urban stream ecology: an assessment of the state of the science. Iournal of the North American Benthological Society 28:1080-1098.

Zhang, L., W. R. Dawes, and G. R. Walker. 2001. Response of mean annual evapotranspiration to vegetation changes at catchment scale. Water Resources Research 37:701-708. 


\section{University Library}

\section{- M I N E R VA \\ A gateway to Melbourne's research publications}

Minerva Access is the Institutional Repository of The University of Melbourne

\section{Author/s:}

Walsh, CJ;Fletcher, TD;Bos, DG;Imberger, SJ

Title:

Restoring a stream through retention of urban stormwater runoff: a catchment-scale experiment in a social-ecological system

\section{Date:}

2015-09-01

\section{Citation:}

Walsh, C. J., Fletcher, T. D., Bos, D. G. \& Imberger, S. J. (2015). Restoring a stream through retention of urban stormwater runoff: a catchment-scale experiment in a social-ecological system. FRESHWATER SCIENCE, 34 (3), pp.1161-1168. https://doi.org/10.1086/682422.

Persistent Link:

http://hdl.handle.net/11343/116487 